Article

\title{
Corporate Sustainability Strategies: A Case Study in Brazil Focused on High Consumers of Electricity
}

\author{
Fabricio Casarejos $1,2, *,+$, Mauricio Nogueira Frota ${ }^{3,+}{ }^{\dagger}$ José Eduardo Rocha ${ }^{3,4}$, \\ Walquíria Rosa da Silva ${ }^{3}$ and José Tenório Barreto Jr. ${ }^{3,4}$ \\ 1 Interdisciplinary Center for the Environment (NIMA), Catholic University of Rio de Janeiro, \\ Rua Marquês de São Vicente, 225-Gávea, Rio de Janeiro-RJ 22453-900, Brazil \\ 2 Climate Change Impacts, Adaptation and Modeling Research Group (CCIAM), Center for Ecology, \\ Evolution and Environmental Changes (CE3C), Faculty of Sciences, Lisbon University, Campo Grande, \\ Lisboa 1749-016, Portugal \\ 3 Postgraduate Program in Metrology for Quality and Innovation, Catholic University of Rio de Janeiro, \\ Rua Marquês de São Vicente, 225-Gávea, Rio de Janeiro-RJ 22453-900, Brazil; frota@esp.puc-rio.br (M.N.F.); \\ jerocha@esp.puc-rio.br (J.E.R.); walquiriarosa8@gmail.com (W.R.d.S.); jose.junior@light.com.br (J.T.B.J.) \\ 4 Light Serviços de Eletricidade S/A, Marechal Floriano, Rio de Janeiro-RJ 20080-002, Brazil \\ * Correspondence: fabricio.casarejos@gmail.com or casarejos@esp.puc-rio.br or casarejos@fc.ul.pt; \\ Tel.: +55-21-3527-1462 \\ + These authors contributed equally to this work.
}

Academic Editor: Marc A. Rosen

Received: 6 July 2016; Accepted: 4 August 2016; Published: 11 August 2016

\begin{abstract}
The decline of socio-ecological resilience has emerged as an unprecedented truth with high risks to local and global economies, thereby increasing the vulnerability of businesses and markets while potentially threatening the wellbeing of civil society as a whole. From a business perspective, corporate strategies towards sustainability are crucial to strengthen the social and economic foundations that foster sustainable development. In order to assist enterprises pursuing leading market positions, this work proposes a set of strategic actions towards sustainability and an evaluation scheme to assess the effectiveness of their implementation process. This proposed global strategy encompasses five key sustainability indices-commitment, investment, difficulty, proactivity and vulnerability-focusing the investigation on a sample of enterprises representing the highest consumers of electricity in the state of Rio de Janeiro, Brazil. Addressing the energy consumption, this study also discusses the concerning level of GHG emissions that are associated with the generation of electricity. Although $85 \%$ of the enterprises participating in this survey recognized the relevance of the actions proposed, the current degree of proactivity and vulnerability associated with these enterprises indicate that very few of them have effectively implemented and invested in corporate sustainability programs, certainly a symptom of their institutional vulnerability.
\end{abstract}

Keywords: sustainable development; climate change; greenhouse gas emissions; corporate carbon strategies and climate change policy; high consumers of electricity

\section{Introduction}

The global challenge of sustainability can be understood as the pursuit of a civilizing project that strikes a balance between development meeting human rights and the maintenance of the Earth's systems in a hospitable and resilient state [1-5].

The decline of socio-ecological resilience has emerged as an unprecedented truth exhibiting high risks to local and global economies, thereby increasing the vulnerability of businesses and markets and potentially threatening the wellbeing of civil society in all nations [6-8]. It will cause structural transformations and disrupt the favorable civilizing conditions with impacts on natural resources and 
ecosystem services, livelihoods and homes, communication, trade, urban and general infrastructure and social conflicts [7-9].

Rockström et al. [1] presents a framework to identify planetary boundaries and to quantify biophysical thresholds of the Earth's systems that must not be transgressed in order to prevent human activities from causing unacceptable environmental change (i.e., climate change; stratospheric ozone depletion; rate of biodiversity loss; change in land use; global freshwater use; ocean acidification; nitrogen and phosphorus cycles; atmospheric aerosol loading; and chemical pollution). More recent studies indicate that anthropogenic pressures on Earth's systems have already reached a scale where abrupt global environmental change can no longer be excluded $[7,8,10,11]$. Although the planetary boundaries are described in terms of separate quantities and processes, their biophysical thresholds are tightly connected. As stated by Steffen et al. [8], transgressing one or more planetary boundaries means transgressing the limits of a safe operating space for human civilization, which could prove deleterious or even catastrophic.

In particular, risks and threats posed by the global phenomenon of climate change present a challenging opportunity for governments and enterprises to reshape their growth strategies and redefine their current values, concepts and operations [12-14]. Between 1750 and 2011, cumulative anthropogenic GHG emissions reached the level of $2040 \pm 310 \mathrm{Gt} \mathrm{CO}_{2 \mathrm{eq}}$ (gigatons of carbon dioxide equivalent) [10]. About $40 \%$ of these emissions $\left(880 \pm 35 \mathrm{Gt} \mathrm{CO}_{2}\right)$ have remained in the atmosphere. Energy production and consumption is the largest source of GHG emissions worldwide, accounting for $71 \%$ of the overall emissions [10].

The pursuit to achieve sustainable development requires the construction of an amalgam of knowledge, strategies and proactive attitudes capable of understanding and addressing the intrinsically complex sense of a just and safe space for human society on Earth [2,8,15]. A true integrated effort to cope with the new era posed by sustainability challenges must be built from coordinated and international collaboration among all actors in developing and developed economies [5,13]. From a business perspective, enterprises must seek innovative and transformative actions and solutions to overcome challenges posed by sustainability, demonstrating leadership and diplomacy in dealing with such a sensitive and threatening matter [16-18]. Enterprises engaged in sustainability must pursue a long-term agenda, where sustainable economic outcomes, the reduction of impacts on the Earth's systems, restrictions of GHG emissions and the strengthening of their relationship with society must be understood as essential compensations for future generations and for the planet as a whole $[2,19,20]$. Corporate sustainability actions are essential to provide the social and economic foundations that foster sustainable development within civil society. As such, they must be integrated into and harmonized within the strategic agenda of the enterprise [21-24].

To ensure the effectiveness of the execution of sustainability actions, there is a distinct need to clarify and quantify any existing opportunities and barriers. As such, an evaluation framework that aids in this is critical to lay the foundation to achieve sustainability targets and goals. This study aims to analyze the proactive attitude towards sustainability, as well as the vulnerability (lack of adherence to the sustainable development precepts) of enterprises responsible for a high consumption of electricity. In pursuing these goals, this work also proposes: a set of strategic actions to foster sustainability within the enterprises' institutional environment and an evaluation scheme to assess the implementation process of the actions proposed (including the five sustainability indices to measure the associated degrees of commitment, difficulty, investment, proactivity and vulnerability).

\section{Corporate Strategies towards Sustainability}

The planetary boundaries framework substantiates the idea that a delimited safe space for human development exists and underlines the groundwork for governance, management and operations $[2,8]$. At the institutional level, this approach challenges policy makers and managers to adequately act in the face of an unknown and unpredictable future reality. In this context, leaders and directors must have the perspicacity to scientifically understand the complexity associated with the challenges of reaching 
global sustainability, preventing against and adapting to the detrimental effects $[12,22,23]$. They must value the benefits of unconventional business models by adopting innovative and transformative actions and solutions for growth and development $[25,26]$.

Furthermore, it is expected that enterprises plan and implement a set of integrated adaptation and mitigation strategies and actions towards sustainability [24,26-28]. The decision-making process must evaluate the costs and potential benefits of sustainability actions to be held at the local, regional and national levels using innovative approaches [20,29]. Metrics and scientific indices that contribute to the measurement of the different aspects of sustainable development while providing guidance in the decision-making process are also necessary $[14,30]$. The availability of technologies and the fair and equitable burden-sharing arrangements should be optimized so as to provide rapid and effective responses. However, managers must not simply pick a single bias and particular policy to address sustainability issues. Corporate strategies towards sustainability should emerge from a fundamental change within the organizational systems, addressing core beliefs and values of the relationship between the enterprise, the market and the natural environment; reaching deep into the institutional domains of the organization [26].

The progress of a worldwide agreement towards sustainability has compelled enterprises to incorporate strategies towards sustainability into their agendas and institutional policies $[12,14,19]$. Many authors have studied and discussed sustainability strategies within the business environment, particularly key topics related to: "climate change strategy" [31]; "climate strategy" [32]; "corporate environmentalism" [25]; "corporate strategies" [25]; "carbon strategies" [33]; "business strategy on climate change" [34]); "the business response to climate change" [21]; "the corporate $\mathrm{CO}_{2}$ strategy" [22]; "corporate carbon strategy" [23]; "climate change and sustainability strategies" [20]. These thematic strategies include the reduction of GHG emissions; the re-evaluation of values, principles, policies and management models; the development of new products towards the expansion of an ethical culture of services, markets and consumption; the adoption of new modes of productivity, competitiveness and relationships; the diagnosis of risks, barriers and emerging opportunities; the establishment of financial and governmental incentives towards sustainability; the formulation of conscious norms and policies; and the anticipation and adaptation to new realities to enable the future use of preventative and control measures.

The trajectory of sustainability is long and turbulent. It requires proactive attitudes from leaders and communities, innovative solutions and commitment to the pursuit of a common ideal of respect for nature as a whole. The resilience of the Earth's systems and the global and local economies depend on human decision-making processes and on the implementation of strategic sustainability actions for the future. In this context, corporate sustainability strategies are understood as an integrated set of values, principles, targets and actions, which are, directly and indirectly, associated with the anthropogenic emissions of GHGs and the other biophysical planetary boundaries of the Earth. These strategies must reflect the institutional priorities and be incorporated into the enterprises' business plan wherever the transition to a low-carbon economy constitutes an essential societal goal.

\section{Methods}

As discussed in previous work [20], Brazilian enterprises exhibiting high electricity consumption reveal low commitment to internationally agreed-upon sustainable development precepts, recommendations and best practices, in particular GHG emissions restrictions. These findings inspired the development of this follow-up survey and in-depth analysis, motivating the understanding of a proactive attitude and vulnerability associated with the lack of managing the challenges and trends posed by sustainability. A follow-up to the prior study, this investigation focuses on a specific group of corporate customers of an electricity utility in Brazil, "Light Serviços de Eletricidade $\mathrm{S} / \mathrm{A}^{\prime \prime}$, the main supplier of electrical energy to 4.1 million consumers in 31 municipalities in the state of Rio de Janeiro, classified by the Brazilian regulatory agency [35] as major consumers of electricity. High-consuming customers of electricity power companies are designated by the Brazilian 
regulating agency. The Brazilian Regulator (Resolution ANEEL 414: 2010) classifies the electrical energy consumption units into three categories: (i) blue hourly rate: $69 \mathrm{~kW}$; (ii) green or blue hourly rate: Less than $69 \mathrm{~kW}$ with a demand higher than or equal to $300 \mathrm{~kW}$; and (iii) blue or green hourly rate: Less than $69 \mathrm{~kW}$ with a demand higher than $300 \mathrm{~kW}$.

Of the 86 enterprises participating in the previous survey [20], 40 agreed to participate in this study, constituting the research sample of this in-depth survey. The sample selection considers the following filtering criteria: (i) high-consumers of electricity [35]; (ii) availability to participate in this survey; and (iii) participation through an internal manager knowledgeable in sustainability-related matters. Devoted to this second-round of the survey, participants demonstrated full commitment to the in-depth analysis, as $100 \%$ of them agreed to respond to the comprehensive questionnaire, helping surveyors clarify subjective issues related to barriers to sustainability and difficulties faced by enterprises in effectively implementing corporate strategies towards sustainability. Considering that the participating enterprises represent high consumers of electricity, the study also assesses the GHG emissions that result from electricity generation.

The sample of enterprises studied covers the following economic sectors, defined according to the taxonomy adopted by the Brazilian Institute of Geography and Statistics (IBGE): manufacturing industry (mining companies, construction companies and factories); commerce (supermarket chains, shopping centers, gas stations and service providers); public organizations (government agencies, banks, hospitals, non-governmental organizations and transportation companies); education and research (higher education institutions, centers of research); and enterprises active in tourism, entertainment and culture.

Aiming to create consciousness within the institutional environment of the enterprise, the proposed approach, the implementation of a set of strategic sustainability actions and an evaluation scheme, was carefully designed to meet the needs and calls to action from prominent international publications related to sustainable development. In this context, recommendations from international organizations active in sustainability and related matters, international best practices and applicable guidelines were identified in the literature and processed to cast the actions proposed and to substantiate this study as a whole.

To ensure the efficacy of the survey, a questionnaire was constructed and tested by a small representative sample of selected entities prior to release. After its validation, the questionnaire was submitted to the participating enterprises. Using their responses, the institutional proactivity and the vulnerability of the participating enterprises was assessed. The questionnaire was organized into four parts addressing the 22 strategic actions proposed, pertaining to three institutional domains of the enterprise's environment (governance; planning and implementation; monitoring and reporting). The first part of the questionnaire includes 6 questions addressing the status of the enterprise's implementation of sustainability actions proposed or the intention to implement them in the short, medium or long term. The second part comprises 5 questions allowing the assessment of the degree of relevance attributed by enterprises to each of the 22 sustainability actions incorporated in the questionnaire. The third part includes 6 questions enabling the assessment of the level of financial investments (measured as a \% of the annual net operating revenue) planned by the participating enterprises towards the implementation of corporate sustainability activities. The fourth part encompasses 16 questions designed to identify the degree of difficulty faced by the participating enterprise throughout the implementation process of the proposed sustainability actions. To enrich the analysis, difficulties faced throughout the implementation of the proposed actions were structured in four dimensions: technical, social and cultural, financial and political and legal. To preserve the individual confidentiality of the participating enterprises, no isolated results are reported; only aggregated answers are conveyed. 


\section{Results and Discussion}

As discussed above, the conception of a set of strategic sustainability actions to reflect the state-of-the-art in sustainability principles and practices constitutes the foundation of this work. Tributes, however, are accredited to the prominent publications, international recommendations and guidelines, which judiciously reflect the current consensus on the most fundamental precepts of sustainable development. The following section discusses the 22 strategic sustainability actions conceived of and presents the evaluation scheme proposed to assess their implementation process. It also describes a set of key sustainability indices conceived of to attribute a grade of proactivity and vulnerability to scale, respectively, different stages of the enterprise in its process of implementing or not implementing the proposed actions. To complete the analysis, the exceedingly high GHG emissions that result from the conventional generation of the electricity consumed by the participating enterprises is also evaluated.

\subsection{Sustainability Actions}

In light of scientific studies, international recommendations and guidelines on best practices towards sustainability, Table 1 describes the 22 strategic actions proposed, which substantiated the construction of the questionnaire administered to the participating enterprises. The actions proposed are associated with different domains of the institutional environment (IE): actions 1-8 refer to the institutional governance; 9-18 to the planning and implementation process of the sustainability actions; while 19-22 acknowledge the monitoring and reporting aspects of the overall process of meeting the criteria of sustainability.

\subsection{Adherence to Sustainability: Findings Revealed by the Questionnaire}

This section presents the results of the questionnaire submitted to the participating enterprises. The 22 sustainability actions (labeled A1-A22) address the three institutional domains of the managerial environment of an enterprise: governance; planning and implementation; monitoring and reporting. Each answer that emerged from the questionnaire was properly scored according to pre-defined criteria. As documented in Tables 2-4, the questionnaire captured four types of information: (i) the status of the implementation of the sustainability actions; (ii) the degree of relevance attributed by enterprises for each sustainability action considered; (iii) the investments in sustainability accomplished or planned by the enterprise; and (iv) the difficulty faced throughout the process of implementing the sustainability actions. These outputs of the questionnaire are discussed in the next three sub-sections.

\subsubsection{Commitment to Sustainability}

For each domain of the institutional environment, Table 2, below, summarizes the status of the implementation process; i.e., sustainability actions effectively implemented or envisioned to be implement in the short (two years), medium (2-6 years) or long term (more than six years). As shown, the following six value scale criteria were adopted: Score 1 (action effectively implemented); Score 0.75 (intention to implement in the short term); Score 0.5 (intention to implement in the middle term); Score 0.25 (intention to implement in the long term); and Score 0 (no intention to implement or no opinion). Table 3 assesses the degree of relevance attributed by enterprises for each of the 22 strategic sustainability actions incorporated into the questionnaire. Similarly, a four-value scale criterion was used; i.e., Score 1 (high degree of relevance assigned); Score 0.50 (medium degree of relevance); Score 0.25 (low degree); and Score 0 (not considered relevant or no opinion). The concept associated with commitment to sustainability reflects not only the confirmed adherence to international recommendations and best practices in sustainability (results presented in the previous study [20]), but also the effectiveness of the enterprise in implementing (or the intention to implement) sustainability actions. 
Table 1. Strategic sustainability actions proposed.

\begin{tabular}{|c|c|c|c|}
\hline IE & \# & Proposed Actions & Formulated From \\
\hline \multirow{8}{*}{ Governance } & 1 & $\begin{array}{l}\text { Include in the institutional charter a section formally committed to promote, monitor and control the research, development and technology innovation } \\
\text { (RD\&I) adherent to the precepts of sustainable development. }\end{array}$ & {$[20,36,37]$} \\
\hline & 2 & Appoint a managerial committee fully committed to sustainability-related matters, empowered to foster such topics among the board of directors. & {$[14,25,26,37,38]$} \\
\hline & 3 & $\begin{array}{l}\text { Develop and implement an annual plan to foster collaboration in RD\&I with governmental and non-governmental institutions committed to the precepts of } \\
\text { sustainable development. }\end{array}$ & {$[12,38-40]$} \\
\hline & 4 & Develop a social responsibility plan to promote social resilience and local developments in sustainability. & {$[2,36,41]$} \\
\hline & 5 & Incorporate the well-established principles of sustainable development into the organizational culture and policies. & {$[15,18,26,42]$} \\
\hline & 6 & Develop projects and corporate programs addressing awareness in sustainability-related matters and knowledge transfer to society. & {$[12,18,43,44]$} \\
\hline & 7 & Ensure effective engagement and participation in relevant fora and events pertaining to sustainability. & {$[12,14,38,45]$} \\
\hline & 8 & Introduce the principles of sustainable development into the organizational culture (e.g., transparency, equity, gender equality and corporate responsibility). & {$[2,14,38]$} \\
\hline \multirow{10}{*}{$\begin{array}{l}\text { Planning and } \\
\text { Implementation }\end{array}$} & 9 & Establish GHG reduction and offset targets as part of the corporate enterprise's primary strategy. & {$[7,18,25,26,33]$} \\
\hline & 10 & Establish the rationalization of the consumption of material supplies and energy resources. & {$[12,46,47]$} \\
\hline & 11 & Implement best practices aimed at reducing pollution and environmental impacts resulting from overall activities performed by the enterprise. & {$[8,42,44,46]$} \\
\hline & 12 & Provide an institutional working environment towards energy efficiency and the mitigation of environmental impacts. & {$[46,48,49]$} \\
\hline & 13 & Implement a systematic benchmarking analysis to define actions, risks and market opportunities to guide the enterprise towards sustainability. & [27-29] \\
\hline & 14 & $\begin{array}{l}\text { Incorporate sustainability into the institutional image of the enterprise as a strategy to disseminate the concept within the institutional environment and to } \\
\text { differentiate its position in the market. }\end{array}$ & {$[19,24,50]$} \\
\hline & 15 & $\begin{array}{l}\text { Perform SWOT analysis (strengths, weaknesses, opportunities and threats) to assess the enterprise's internal status on matters related to the physical, } \\
\text { regulatory and socioeconomic impacts of climate change. }\end{array}$ & {$[25,29,39]$} \\
\hline & 16 & Identify opportunities to create new, innovative business ventures that respond to the demands posed by sustainability. & {$[16,17,34]$} \\
\hline & 17 & Promote the training and qualification of human resources aligned with the issues and challenges of sustainability. & {$[19,36,51,52]$} \\
\hline & 18 & Implement a system of green procurement and promote conscientious consumption. & {$[17,46,53]$} \\
\hline \multirow{4}{*}{$\begin{array}{l}\text { Monitoring and } \\
\text { Reporting }\end{array}$} & 19 & Monitor material and energy flows throughout the life cycle and supply chain. & {$[30,38,46,48]$} \\
\hline & 20 & Prepare, publish and disseminate an annual sustainability report and GHG emissions report. & {$[19,30,48]$} \\
\hline & 21 & Evaluate the social, cultural, economic and environmental impacts resulting from the activities developed by the enterprise. & {$[14,30,38,54]$} \\
\hline & 22 & Diagnose the motivation and wellbeing of the employees and carry out stakeholder and shareholder satisfaction analysis based on the actions performed. & {$[20,36,38]$} \\
\hline
\end{tabular}


Table 2. Questionnaire output: status of the implementation of the sustainability actions.

\begin{tabular}{|c|c|c|c|c|c|c|c|c|c|c|c|c|c|c|c|c|c|c|c|c|c|c|c|}
\hline \multirow{3}{*}{$\begin{array}{c}\text { Status of the } \\
\text { Implementation Process }\end{array}$} & \multirow{3}{*}{ Score } & \multicolumn{22}{|c|}{ Sustainability Actions Structured in Three Institutional Domains } \\
\hline & & \multicolumn{8}{|c|}{ Governance } & \multicolumn{10}{|c|}{ Planning and Implementation } & \multicolumn{4}{|c|}{ Monitoring and Reporting } \\
\hline & & A1 & A2 & A3 & A4 & A5 & A6 & A7 & A8 & A9 & A10 & A11 & A12 & A13 & A14 & A15 & A16 & A17 & A18 & A19 & A20 & A21 & A22 \\
\hline Effectively Implemented & 1.00 & 16 & 20 & 16 & 28 & 36 & 20 & 12 & 12 & 24 & 40 & 60 & 44 & 16 & 12 & 24 & 20 & 28 & 32 & 32 & 20 & 28 & 32 \\
\hline Short term (2 years) & 0.75 & 8 & 4 & 16 & 24 & 12 & 12 & 16 & 24 & 36 & 40 & 12 & 32 & 20 & 28 & 16 & 12 & 36 & 24 & 24 & 16 & 20 & 20 \\
\hline Middle term (2-6 years) & 0.50 & 24 & 28 & 8 & 26 & 16 & 20 & 12 & 8 & 12 & 12 & 4 & 8 & 24 & 20 & 12 & 20 & 4 & 12 & 8 & 20 & 8 & 8 \\
\hline No intent to implement & 0 & 24 & 24 & 28 & 4 & 4 & 12 & 16 & 8 & 4 & 0 & 4 & 4 & 12 & 16 & 16 & 20 & 8 & 8 & 8 & 12 & 16 & 8 \\
\hline No opinion & 0 & 12 & 12 & 12 & 4 & 8 & 16 & 24 & 20 & 16 & 4 & 16 & 4 & 20 & 20 & 24 & 20 & 8 & 16 & 16 & 24 & 12 & 20 \\
\hline
\end{tabular}

Table 3. Questionnaire output: the degree of relevance attributed by enterprises for each sustainability action.

\begin{tabular}{|c|c|c|c|c|c|c|c|c|c|c|c|c|c|c|c|c|c|c|c|c|c|c|c|}
\hline \multirow{4}{*}{ Degree of Relevance } & \multirow{4}{*}{ Score } & \multicolumn{22}{|c|}{ Sustainability Actions Proposed Structured in Three Institutional Domains } \\
\hline & & \multicolumn{8}{|c|}{ Governance } & \multicolumn{10}{|c|}{ Planning and Implementation } & \multicolumn{4}{|c|}{ Monitoring and Reporting } \\
\hline & & A1 & A2 & A3 & A4 & A5 & A6 & A7 & A8 & A9 & A10 & A11 & A12 & A13 & A14 & A15 & A16 & A17 & A18 & A19 & A20 & A21 & A22 \\
\hline & & \multicolumn{22}{|c|}{ Results Expressed as a Percentage of the Total Number of Enterprises Participating in the Survey (\%) } \\
\hline High & 1.00 & 18 & 33 & 24 & 48 & 47 & 43 & 19 & 19 & 33 & 47 & 48 & 57 & 24 & 19 & 24 & 19 & 33 & 37 & 33 & 24 & 37 & 43 \\
\hline Medium & 0.50 & 29 & 29 & 43 & 37 & 33 & 33 & 33 & 52 & 43 & 43 & 38 & 33 & 52 & 38 & 33 & 43 & 57 & 48 & 29 & 27 & 43 & 42 \\
\hline Low & 0.25 & 43 & 24 & 24 & 10 & 10 & 14 & 29 & 10 & 5 & 10 & 0 & 5 & 14 & 29 & 24 & 14 & 5 & 10 & 33 & 29 & 10 & 10 \\
\hline Not relevant & 0 & 10 & 4 & 5 & 0 & 0 & 0 & 5 & 0 & 0 & 0 & 0 & 0 & 0 & 0 & 0 & 5 & 0 & 0 & 0 & 10 & 5 & 0 \\
\hline No opinion & 0 & 0 & 10 & 4 & 5 & 10 & 10 & 14 & 19 & 19 & 0 & 14 & 5 & 10 & 14 & 19 & 5 & 5 & 5 & 5 & 10 & 5 & 5 \\
\hline
\end{tabular}




\subsubsection{Investments in Sustainability}

Table 4 reports the results of the assessment considering the level of financial investments accomplished or planned to be accomplished by the participating enterprises. The financial investment (labeled in) is expressed as a percent of the annual financial performance (annual net operating revenue) accomplished by the enterprise. The treatment of the data captured through the questionnaire considers the following three investment periods: short- (two years), medium- (2-6 years) and long-term (more than six years). The analysis considered a five-value scale, i.e., Score 1 (inv $>5 \%$ ); score $0.75(1 \%<i n v \leq 5 \%)$; Score $0.50(0.5 \%<i n v \leq 1 \%)$; Score $0.25(0 \%<i n v \leq 0.5 \%)$; Score 0 (inv $=0$, or not reported).

Table 4. Questionnaire output: investments (in) in sustainability activities.

\begin{tabular}{|c|c|c|c|c|}
\hline $\begin{array}{c}\text { Level of } \\
\text { Investment }\end{array}$ & \multirow{2}{*}{ Score } & $\begin{array}{l}\text { Short-Term } \\
\text { Investment }\end{array}$ & $\begin{array}{l}\text { Middle-Term } \\
\text { Investment }\end{array}$ & $\begin{array}{l}\text { Long-Term } \\
\text { Investment }\end{array}$ \\
\hline $\begin{array}{l}\text { Percentage of the } \\
\text { Annual Revenue }\end{array}$ & & \multicolumn{3}{|c|}{$\begin{array}{l}\text { Results Expressed in Percentage of the Total Number } \\
\text { of Enterprises Participating in the Survey (\%) }\end{array}$} \\
\hline Not reported & 0 & 24 & 31 & 31 \\
\hline$i n v=0$ & 0 & 19 & 6 & 0 \\
\hline $0 \%<i n v \leq 0.5 \%$ & 0.25 & 25 & 19 & 19 \\
\hline $0.5 \%<i n v \leq 1 \%$ & 0.50 & 13 & 25 & 19 \\
\hline $1 \%<i n v \leq 5 \%$ & 0.75 & 19 & 19 & 25 \\
\hline$i n v>5 \%$ & 1.00 & 0 & 0 & 6 \\
\hline
\end{tabular}

\subsubsection{Difficulties Associated with the Implementation of Sustainability Actions}

Table 5 summarizes the results of the assessment of the degree of difficulty faced by the respondent enterprises throughout the implementation process of the actions proposed. The treatment of the data captured by the questionnaire considered four possible dimensions of difficulty (technical, social and cultural, financial, political and legal). The participants of the survey attributed a grade to each difficulty they faced throughout the implementation of the sustainability actions. The answers given to the questions posed by the questionnaire were processed based on the following three-value scale criterion: Score 1 (no opinion or high degree of difficulty); Score 0.50 (moderate degree); Score 0 (low degree). 
Table 5. Questionnaire output: difficulty of the implementation of sustainability actions.

\begin{tabular}{|c|c|c|c|c|c|c|c|c|c|c|c|c|c|c|c|c|c|c|c|c|c|c|c|c|}
\hline \multirow{4}{*}{$\begin{array}{l}\text { Dimension of } \\
\text { Difficulty }\end{array}$} & \multirow{4}{*}{$\begin{array}{l}\text { Degree of } \\
\text { Difficulty }\end{array}$} & \multirow{4}{*}{ Score } & \multicolumn{22}{|c|}{ Sustainability Actions Structured in Three Institutional Domains } \\
\hline & & & \multicolumn{8}{|c|}{ Governance } & \multicolumn{10}{|c|}{ Planning and Implementation } & \multicolumn{4}{|c|}{ Monitoring and Reporting } \\
\hline & & & A1 & A2 & A3 & A4 & A5 & A6 & A7 & A8 & A9 & A10 & A11 & A12 & A13 & A14 & A15 & A16 & A17 & A18 & A19 & A20 & A21 & A22 \\
\hline & & & \multicolumn{22}{|c|}{ Results Expressed as a Percentage of the Total Number of Enterprises Participating in the Survey (\%) } \\
\hline \multirow{4}{*}{ Technical } & No opinion & 1.0 & 55 & 68 & 50 & 61 & 67 & 78 & 61 & 55 & 37 & 62 & 51 & 50 & 38 & 49 & 43 & 50 & 56 & 49 & 56 & 56 & 50 & 61 \\
\hline & High & 1.0 & 28 & 22 & 28 & 17 & 11 & 0 & 6 & 11 & 19 & 6 & 6 & 0 & 50 & 13 & 13 & 13 & 19 & 13 & 22 & 22 & 17 & 11 \\
\hline & Moderate & 0.5 & 11 & 10 & 11 & 22 & 11 & 11 & 22 & 17 & 31 & 19 & 31 & 31 & 6 & 19 & 25 & 31 & 19 & 25 & 11 & 11 & 22 & 11 \\
\hline & Low & 0 & 6 & 0 & 11 & 0 & 11 & 11 & 11 & 17 & 13 & 13 & 12 & 19 & 6 & 19 & 19 & 6 & 6 & 13 & 11 & 11 & 11 & 17 \\
\hline \multirow{4}{*}{ Social and Cultural } & No opinion & 1.0 & 60 & 67 & 61 & 55 & 64 & 67 & 61 & 44 & 62 & 100 & 75 & 56 & 69 & 62 & 55 & 62 & 50 & 49 & 76 & 67 & 53 & 39 \\
\hline & High & 1.0 & 28 & 22 & 28 & 17 & 22 & 11 & 17 & 22 & 6 & 0 & 6 & 6 & 6 & 6 & 13 & 19 & 13 & 19 & 11 & 11 & 19 & 11 \\
\hline & Moderate & 0.5 & 6 & 11 & 0 & 17 & 11 & 11 & 11 & 17 & 19 & 0 & 13 & 19 & 19 & 13 & 13 & 13 & 31 & 19 & 11 & 11 & 17 & 33 \\
\hline & Low & 0 & 6 & 0 & 11 & 11 & 11 & 11 & 11 & 17 & 13 & 0 & 6 & 19 & 6 & 19 & 19 & 6 & 6 & 13 & 2 & 11 & 11 & 17 \\
\hline \multirow{4}{*}{ Financial } & No opinion & 1.0 & 33 & 67 & 49 & 67 & 61 & 61 & 56 & 61 & 50 & 50 & 62 & 18 & 82 & 56 & 49 & 57 & 31 & 25 & 61 & 61 & 61 & 55 \\
\hline & High & 1.0 & 44 & 22 & 28 & 11 & 17 & 17 & 11 & 11 & 6 & 6 & 0 & 13 & 6 & 6 & 13 & 12 & 19 & 31 & 17 & 17 & 6 & 6 \\
\hline & Moderate & 0.5 & 17 & 11 & 17 & 11 & 11 & 11 & 22 & 11 & 31 & 31 & 25 & 50 & 6 & 19 & 19 & 25 & 44 & 31 & 11 & 11 & 22 & 22 \\
\hline & Low & 0 & 6 & 0 & 6 & 11 & 11 & 11 & 11 & 17 & 13 & 13 & 13 & 19 & 6 & 19 & 19 & 6 & 6 & 13 & 11 & 11 & 11 & 17 \\
\hline \multirow{4}{*}{ Political and Legal } & No opinion & 1.0 & 61 & 83 & 72 & 78 & 72 & 78 & 67 & 50 & 81 & 74 & 88 & 75 & 81 & 75 & 55 & 88 & 82 & 68 & 78 & 78 & 78 & 83 \\
\hline & High & 1.0 & 22 & 6 & 11 & 0 & 6 & 0 & 11 & 11 & 0 & 0 & 0 & 0 & 0 & 0 & 13 & 0 & 0 & 0 & 0 & 0 & 0 & 0 \\
\hline & Moderate & 0.5 & 11 & 11 & 6 & 11 & 11 & 11 & 11 & 22 & 6 & 13 & 6 & 6 & 13 & 6 & 13 & 6 & 12 & 19 & 11 & 11 & 11 & 0 \\
\hline & Low & 0 & 6 & 0 & 11 & 11 & 11 & 11 & 11 & 17 & 13 & 13 & 6 & 19 & 6 & 19 & 19 & 6 & 6 & 13 & 11 & 11 & 11 & 17 \\
\hline
\end{tabular}




\subsection{Measuring Allegiance to Sustainability Related Matters}

This section presents an evaluation scheme to assess the degree of proactivity and vulnerability of the enterprises associated with the implementation process of the proposed sustainability actions. Three indices are proposed to measure the degree of commitment, investment and technical and financial difficulty faced by the enterprises throughout this process. A fourth and a fifth index are conceived of to allow for the assessment of the overall institutional proactivity and vulnerability faced by the respondent enterprises when called to overcome challenges and risks related to sustainability matters. Figure 1 depicts the structure of the evaluation scheme proposed, which acknowledges the three domains of the institutional environment (governance, planning and implementation, monitoring and reporting).

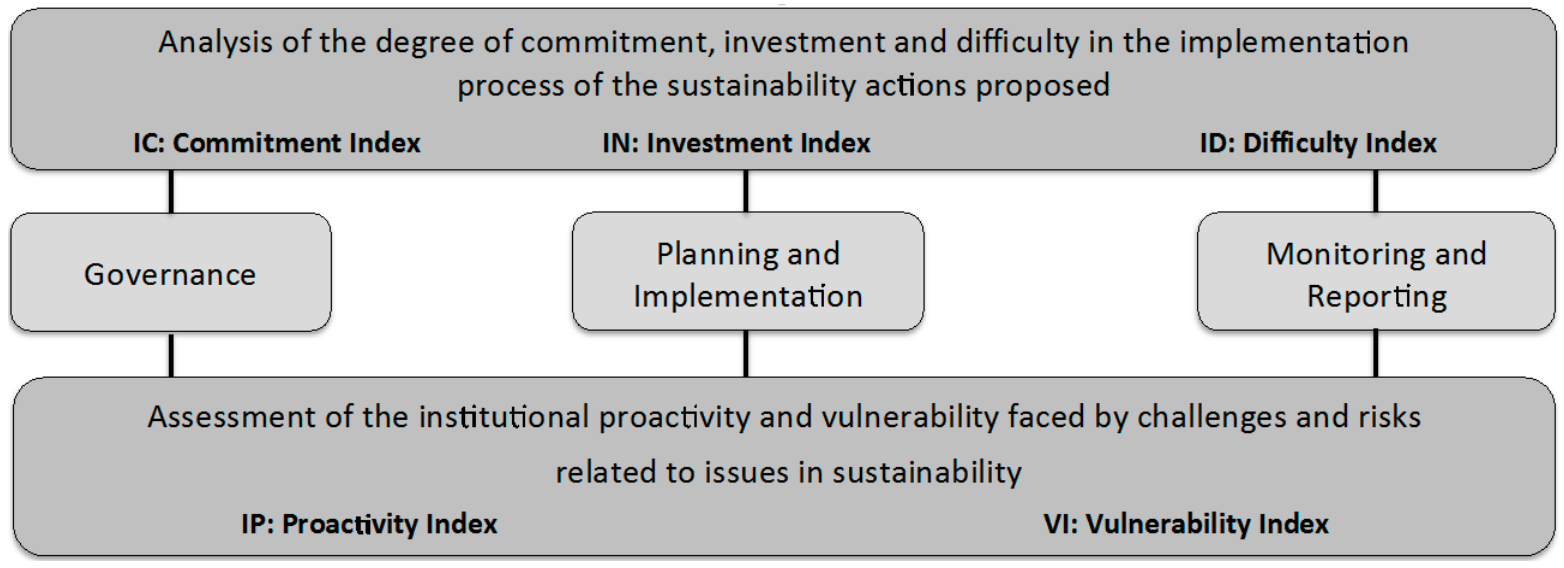

Figure 1. Structure of the institutional evaluation scheme proposed.

This evaluation scheme measures proactivity towards sustainability and exposure to vulnerability based on three linked indices: the commitment index, the investment index and the difficulty index, each discussed below.

\subsubsection{Commitment Index}

The Commitment Index (IC), defined in Equation (1), accounts for the outputs of the questionnaire associated with the first two aspects summarized in Tables 2 and 3; i.e., the actual status of the implementation process of sustainability actions and the degree of relevance attributed to each action proposed. The IC was conceived of to measure the degree of commitment of the respondent enterprises throughout the implementation process of the sustainability actions proposed. The IC is then calculated by summing the individual scores attributed to each answer given by the respondents of the questionnaire, for each one of the three managerial domains of the institutional environment (governance, planning and implementation, monitoring and reporting) considered in the analysis.

$$
\begin{aligned}
I C=\frac{1}{6 . N . T} \sum_{\alpha=1}^{N} & {\left[\frac{1}{M} \sum_{\beta=1}^{8}\left(\sum_{\gamma=1}^{6} \mathcal{A}_{\gamma}+\sum_{\delta=1}^{5} \Re_{\delta}\right)_{\beta}\right.} \\
& \left.+\frac{1}{M^{\prime}} \sum_{\beta=9}^{18}\left(\sum_{\gamma=1}^{6} \mathcal{A}_{\gamma}^{\prime}+\sum_{\delta=1}^{5} \Re_{\delta}^{\prime}\right)_{\beta}+\frac{1}{M^{\prime \prime}} \sum_{\beta=19}^{22}\left(\sum_{\gamma=1}^{6} \mathcal{A}^{\prime \prime} \gamma+\sum_{\delta=1}^{5} \Re^{\prime \prime} \delta\right)_{\beta}\right]_{\alpha}
\end{aligned}
$$

\subsubsection{Investment Index}

The Investment Index (IN), defined in Equation (2), accounts for investments in sustainability activities performed (Table 4). It was conceived of to account for financial investments planned by the 
participating enterprises towards the implementation of corporate sustainability activities. The $I N$ is calculated by summing the individual contribution of the scores attributed in each answer declared by the respondents, taking into account all three investment periods considered (short, medium and long term) in the analysis.

$$
I N=\frac{1}{3 N} \sum_{\alpha=1}^{N}\left[\sum_{\rho=1}^{5}\left(\frac{S_{\rho}}{T}+\frac{M_{\rho}}{T^{\prime}}+\frac{L_{\rho}}{T^{\prime \prime}}\right)\right]_{\alpha}
$$

\subsubsection{Difficulty Index}

The Difficulty Index (ID), defined in Equation (3), processes the outputs of the questionnaire (Table 5) to measure the degree of difficulty faced by the enterprises throughout the implementation process of the actions proposed. The ID is then calculated by summing the individual contribution of the scores attributed in each answer declared by the respondents, taking into account all four dimensions of difficulty (technical; social and cultural; financial; and political and legal).

$$
\begin{aligned}
I D=\frac{1}{12 \cdot N \cdot Q \cdot R} & \sum_{\alpha=1}^{N}\left\{\sum _ { \mu = 1 } ^ { 1 6 } \left[\sum_{\beta=1}^{8}(T E+S C+F I+P L)_{\beta}+\sum_{\beta=9}^{18}\left(T E^{\prime}+S C^{\prime}+F I^{\prime}+P L^{\prime}\right)_{\beta}\right.\right. \\
& \left.\left.+\sum_{\beta=19}^{22}\left(T E^{\prime \prime}+S C^{\prime \prime}+F I^{\prime \prime}+P L^{\prime \prime}\right)_{\beta}\right]_{\mu}\right\}_{\alpha}
\end{aligned}
$$

In Equation (1), the parameter $T(T=11)$ represents the number of questions posed by the questionnaire to address the first two analyses discussed above in Section 4.2.1. Parameters $M, M^{\prime}$ and $M^{\prime \prime}$ denote the total number of responses required to obtain the maximum score for each domain of the institutional environment considered (for the present study: $M=6 ; M^{\prime}=7 ; M^{\prime \prime}=3$ ). The variable $\mathcal{A}$ denotes the score attributed to each answer associated with the status of the implementation of the actions proposed, and $\Re$ denotes the score attributed to each answer associated with the degree of relevance attributed by enterprises for each action.

In Equation (2), the summation operators are applied to the arguments $S, M$ and $L$, which denote financial investments planned by the participating enterprises towards the implementation of corporate sustainability activities in the short, middle and long term (Table 3), as discussed in Section 4.2.2. Index $\rho$ counts the scores for each range of the financial investment (annual net operating revenue) accomplished by the enterprise. The result of each summation is normalized with the parameters $T, T^{\prime}$ and $T^{\prime \prime}$, denoting the total number of responses obtained in each length of the investment periods.

In Equation (3), the parameter $Q$ denotes the number of questions discussed in Section 4.2.3. In the present study, $Q=16$ accounted for the four possible answers displayed in the questionnaire (high; moderate; low degree of difficulty; and no opinion) and for each of the four dimension of difficulty (technical, TE; social and cultural, SC; financial, FI and political and legal, $P L$ ). $R$ is a normalized parameter to limit the result of each summation (in this study, $R=22$ denotes the total sustainability actions proposed).

In the equations above, $N$ is the total number of enterprises participating in the survey. The absence of apostrophe, a single apostrophe (symbol ') and a double apostrophe (symbol ") are associated with variables used to identify the domain of the institutional environment referred in the analysis; i.e., governance, planning and implementation and monitoring and reporting. The Greek letters $\alpha$ ( 1 to $N), \beta, \gamma, \delta, \mu$ are indices of the summation operator, in which $\beta$ ( 1 to 8 ) refers to sustainability actions in governance, $\beta$ (9 to 18) to actions in planning and implementation and $\beta$ (19 to 22 ) to actions in monitoring and reporting. Indices IC, IN and ID vary from a minimum value of zero to a maximum value of one, featuring the situation associated with a maximum degree of commitment, investment and difficulty. 


\subsubsection{Estimating Institutional Proactivity}

The degree of institutional proactivity is measured by a combination of both the Commitment Index (IC) and the Investment Index (IN), yielding the Institutional Proactivity Index (IP), given in Equation (4). Notice that this equation accounts for the fact that with a higher degree of difficulty comes a lower degree of effectiveness of implementation of the actions proposed. This index affords clarification of the proactive attitude of the organizations towards the challenges posed by sustainability. $I P$ varies from a minimum value of zero (minimum degree of institutional proactivity) to a maximum value of one (maximum degree of institutional proactivity).

$$
I P=\frac{I C+I N}{2}
$$

\subsubsection{Estimating the Degree of Vulnerability}

The degree of institutional vulnerability is measured by a combination of the above three indices, yielding the Institutional Vulnerability Index (VI), given in Equation (5). This equation accounts for the fact that a higher degree of difficulty implies a higher institutional vulnerability for enterprises that do not properly cope with the challenges and demands posed by sustainability. Furthermore, the higher the degree of commitment and investment, the higher the effectiveness of the process associated with the implementation of the actions proposed.

$$
V I=I D^{2}-I C \cdot I N
$$

The index VI varies from a minimum (negative) value of -1 (minimum degree of institutional vulnerability) to a maximum (positive) value of one (maximum degree of institutional vulnerability). Note that $V I=0$ indicates a balance between the degree of difficulty faced by the organization in the implementation process of the proposed actions and the degree of commitment and investments realized. The $-1<V I \leq 0$ range suggests a proactive attitude by the enterprises participating in the survey towards sustainability. The $0<V I \leq 1$ range signifies a substantial degree of vulnerability.

The equations above can be applied either to a single enterprise $(N=1)$ or to multiple enterprises belonging to a specific economic sector or to all enterprises participating in the survey.

\subsection{Survey Findings: Statistical Analysis}

This section presents the statistical analyses performed after the application of a "best fit" analysis to a probability distribution curve (as summarized in Figures 2-4; real data: dark gray color; beta distribution: light gray color). The beta distribution curve was identified as the curve of probability yielding the greatest adherence to the survey data; the chi-square hypothesis test $\left(\mathrm{x}^{2}\right)$ performed at a confidence level of $99 \%$ (significance level of $1 \%$ ) confirms that the actual data exhibits a beta distribution curve. This distribution enables the definition of distinct groupings in terms of the corresponding percentiles ( $25 \%, 50 \%, 75 \%$ and $100 \%$ ) of the sample. The results of the indices $C I, I N$ and ID are interpreted by the range of the scores accumulated, denoted as follows: very high: $0.56<\mathrm{I}$ $[\mathrm{C}, \mathrm{N}, \mathrm{D}] \leq 1.0$; high: $0.42<\mathrm{I}[\mathrm{C}, \mathrm{N}, \mathrm{D}] \leq 0.56$; moderate (near average): $0.29<\mathrm{I}[\mathrm{C}, \mathrm{N}, \mathrm{D}] \leq 0.42$; and low: I $[\mathrm{C}, \mathrm{N}, \mathrm{D}] \leq 0.29$.

The proposed metrics, given in Equations (1)-(3), were used as a reference to calculate the degrees of commitment, investment and difficulty for the entire sample $(N=40)$ based on the questionnaire output data (Tables 2-5). The descriptive statistics for the entire sample $(N=40)$ reveal a moderate degree of commitment, $I C=0.38$ (mean $=0.38$, standard deviation $=0.20$ ); a low degree of investment, $I N=0.17$ (mean $=0.14$, standard deviation $=0.09)$; and a very high degree of difficulty, $I D=0.96$ $($ mean $=0.96$, standard deviation $=0.06)$. Equations $(4)$ and $(5)$ were used to calculate $I P$ and VI, revealing a low degree of institutional proactivity, $I P=0.28$, and a very high degree of institutional vulnerability, $V I=0.83$. 


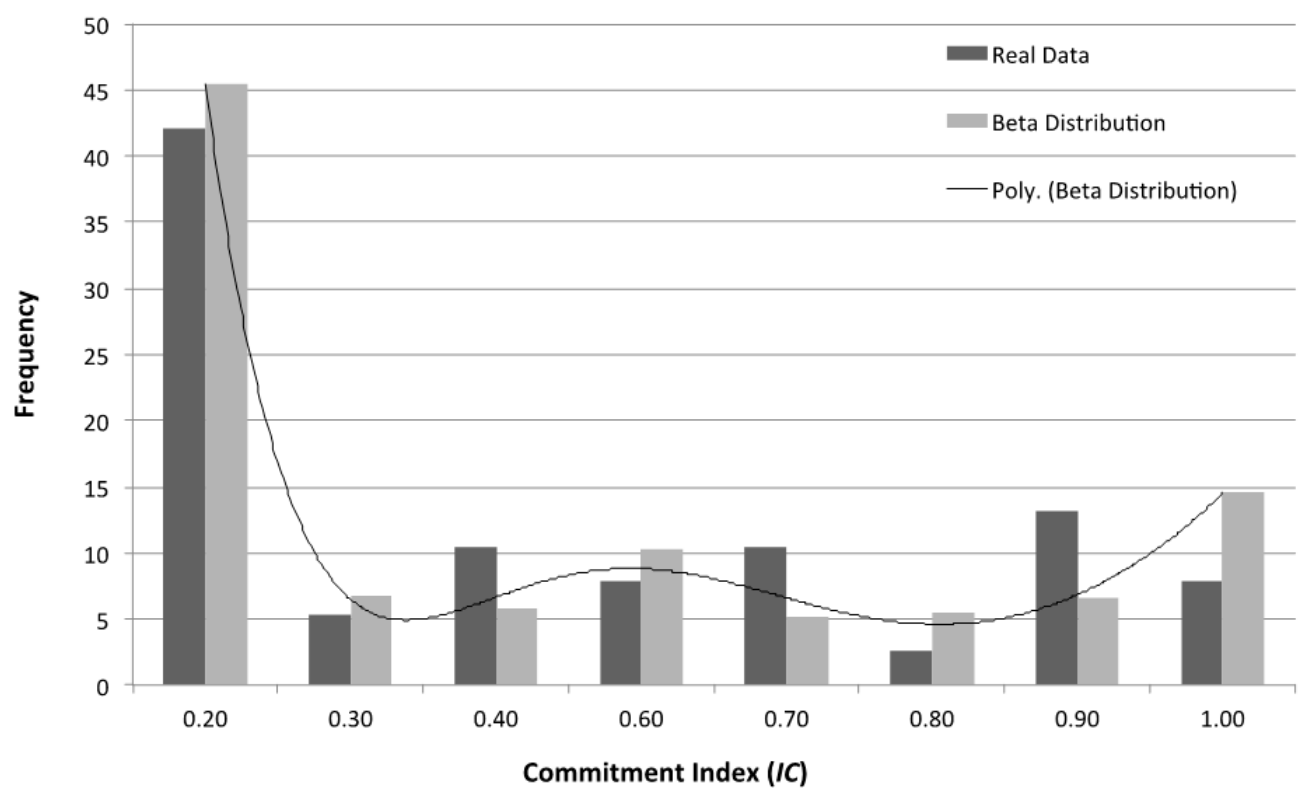

Figure 2. Statistical analysis of the commitment index, which accounts for the status of the implementation process of sustainability actions and the degree of relevance attributed to each action proposed.

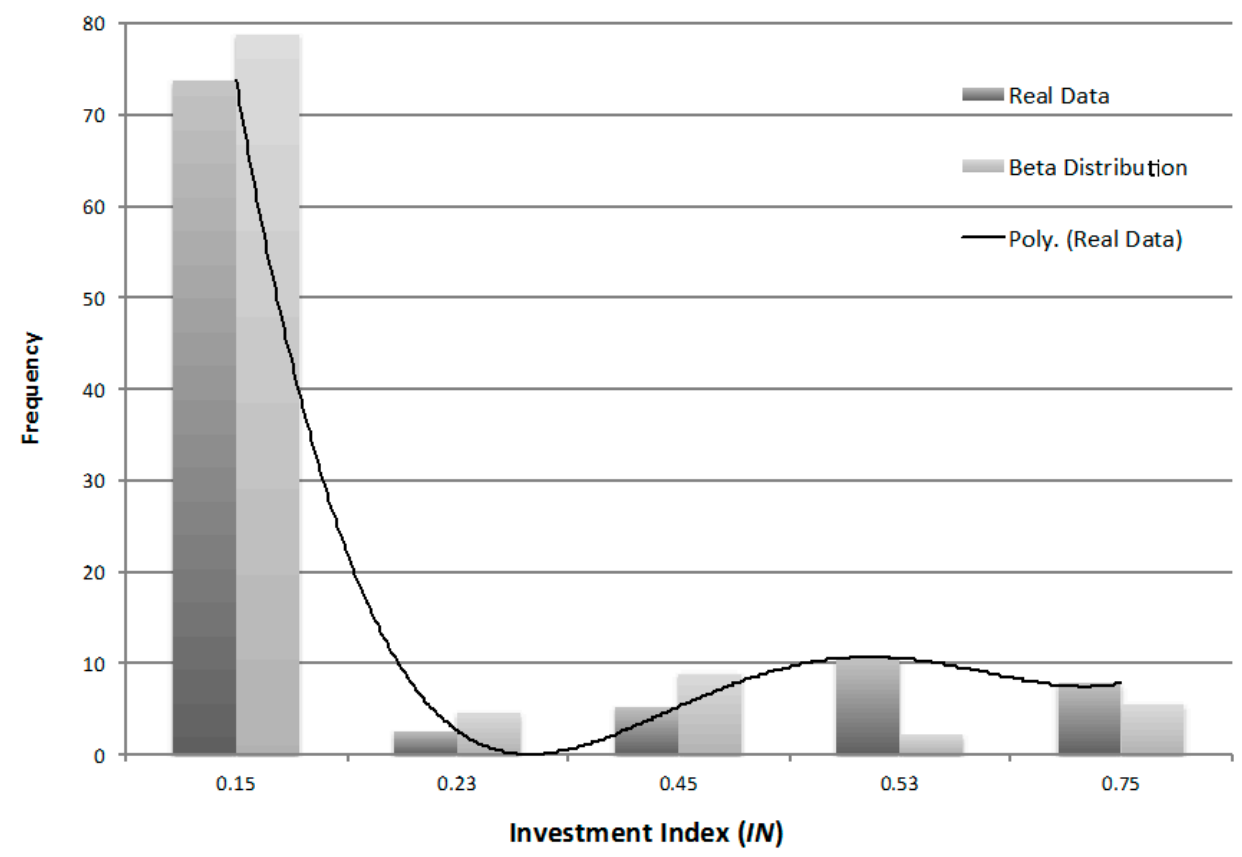

Figure 3. Statistical analysis of the investment index, which accounts for financial investments planned by the participating enterprises towards the implementation of corporate sustainability activities. 


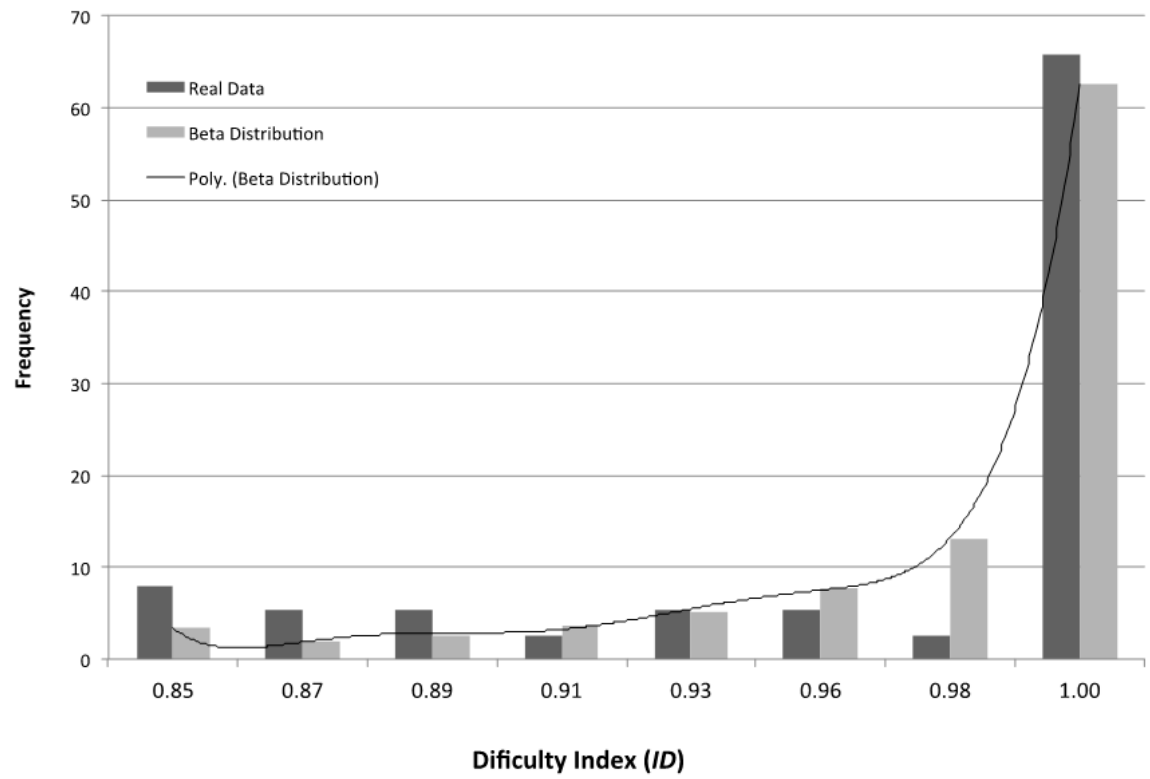

Figure 4. Statistical analysis of the difficulty index, which measures the degree of difficulty faced by the enterprises throughout the implementation process of the actions proposed.

\subsection{Allegiance to Sustainability and Accounting for GHG Emissions}

This section presents an overall analysis of the proposed indices, whose calculation was fragmented by economic sector, i.e., "manufacturing industry", "commerce", "public organizations", "education and research" and "tourism, entertainment and culture". The aggregated results of this analysis are shown in Table 6, which summarizes all of the specificities for the different economic sectors. Based on this analysis, the total GHG emissions associated with the generation of the electrical energy consumed was calculated and reported pictorially.

Table 6. Calculated indices and GHG emissions from the generation of electricity.

\begin{tabular}{|c|c|c|c|c|c|c|c|c|c|c|}
\hline \multicolumn{2}{|c|}{ Enterprises Classified by Economic Sector } & \multicolumn{5}{|c|}{ Indices } & \multicolumn{2}{|c|}{$\begin{array}{c}\text { Annual Energy } \\
\text { Consumption (MWh) }\end{array}$} & \multicolumn{2}{|c|}{$\begin{array}{l}\left.{ }^{*}\right) \text { Average Annual GHG } \\
\left.\text { Emissions (t } \mathrm{CO}_{2 \mathrm{eq}}\right)\end{array}$} \\
\hline Sector & $\mathbf{N}$ & IC & $I N$ & $I D$ & $I P$ & VI & By Sector & By Unit & By Sector & By Unit \\
\hline Manufacturing & 10 & 0.49 & 0.30 & 0.94 & 0.40 & 0.69 & 11,716 & 1172 & 1666 & 157 \\
\hline Commerce & 16 & 0.25 & 0.12 & 0.98 & 0.18 & 0.94 & 66,871 & 4179 & 9509 & 594 \\
\hline Public Organizations & 4 & 0.65 & 0.19 & 0.90 & 0.42 & 0.65 & 279,288 & 69,822 & 39,715 & 9929 \\
\hline Education and Research & 4 & 0.18 & 0 & 1.0 & 0.09 & 1.0 & 2848 & 712 & 405 & 101 \\
\hline Tourism, Entertainment and Culture & 6 & 0.57 & 0.22 & 0.96 & 0.39 & 0.73 & 20,410 & 3402 & 2902 & 484 \\
\hline All economic sectors & 40 & 0.38 & 0.17 & 0.96 & 0.28 & 0.83 & 381,134 & 9528 & 54,197 & 1355 \\
\hline
\end{tabular}

* Emissions volumes are given in GHG emission equivalents, which are derived from the generation of the energy consumed from January 2015-December 2015; calculated based on a conversion factor (annual average) of $0.1422 \mathrm{t} \mathrm{CO}_{2 \mathrm{eq}} / \mathrm{MWh}$. Source: Brazilian Ministry of Science, Technology and Innovation: [55].

Figure 5 depicts the commitment and difficulty indices related to the GHG emissions that result from the generation of the electrical energy consumed by the enterprises classified by the following five economic sectors: 1-Manufacturing Industry; 2-Commerce; 3-Public Organizations; 4-Education \& Research and 5-Tourism, Entertainment \& Culture. Figure 6 depicts the proactivity and vulnerability indices related to the same GHG emissions. In these pictorial representations, the volumes of the spheres (one for each economic sector) are proportional to the level of GHG emissions. Lighter areas (leftmost position) indicate the worst scenarios of the enterprises' commitment and institutional proactivity in the implementation of the sustainability actions proposed. 


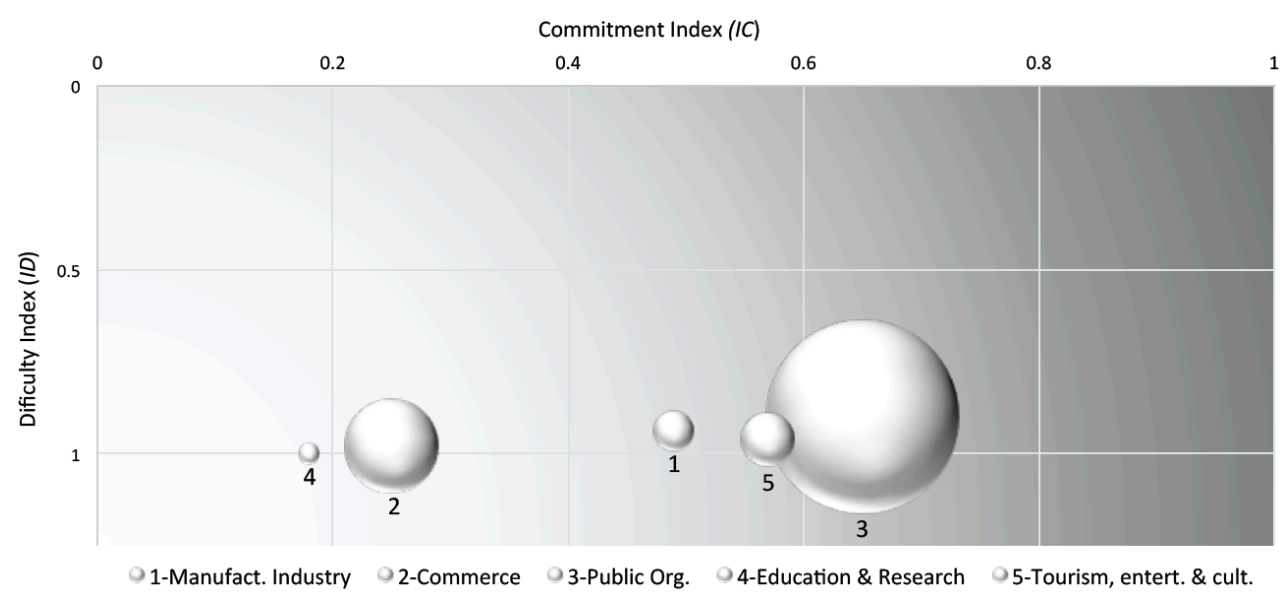

Figure 5. Commitment and difficulty indices related to the GHG emissions.

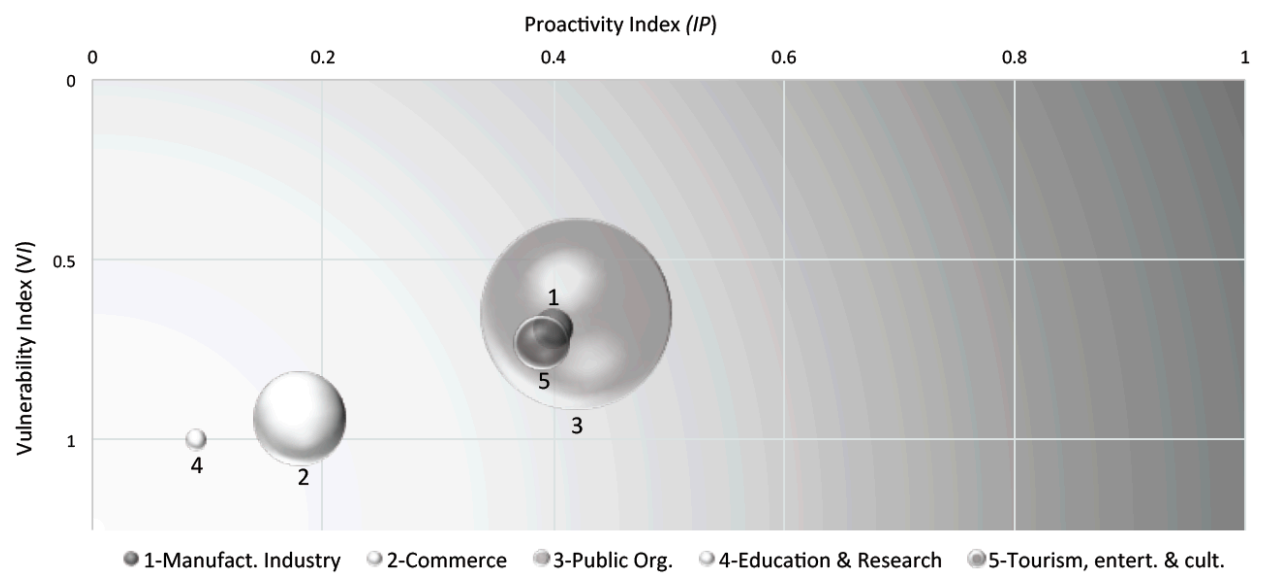

Figure 6. Proactivity and vulnerability indices related to the GHG emissions.

The study revealed that public organizations are considered to be the largest emitters of GHG (9509 $\mathrm{t} \mathrm{CO}_{2 \text { eq }}$ by sector, $17.5 \%$ of the total emission of the entire sample), exhibiting the highest degree of institutional proactivity $(I P=0.42)$ and the lowest degree of institutional vulnerability $(V I=0.65)$. Education and research institutions were shown to be the smallest emitters of GHG ( $405 \mathrm{t} \mathrm{CO}_{2 \mathrm{eq}}$ by sector), exhibiting the smallest degree of institutional proactivity $(I P=0.09)$ and the highest degree of institutional vulnerability $(V I=1.0)$. While commerce enterprises can be associated with a low degree of institutional proactivity and a very high degree of vulnerability, the manufacturing industry and tourism, entertainment and culture enterprises exhibited a moderate degree of institutional proactivity and a very high degree of vulnerability.

Although around $85 \%$ of the enterprises participating in this survey attributed relevance to the strategic actions prioritized, their current degree of proactivity and level of intent to implement these actions suggests a lack of the production of short-term results. The degree of proactivity was ranked "low" and the degree of vulnerability ranked "very high", indicating that there are very few enterprises that have effectively implemented and invested in corporate programs and activities towards sustainability; a result that suggests a substantial level of vulnerability. This should be perceived as a matter of concern as it indicates little or no effect on the overall reduction of GHG emissions.

Especially, the results regarding Actions 9-12, 19 and 20 indicate a low level of carbon management activities, suggesting that enterprises are neither aligned with the Brazilian Climate Change Policy [48] nor with the global effort to reduce GHG emissions $[13,38]$. It calls attention to an immediate necessity 
to implement actions and policies towards the reduction of GHG emissions within a Brazilian national context [20,48]. Policymakers should engage enterprises by implementing carbon policy measures and climate change adaptation and mitigation strategies $[14,23,28]$.

Additionally, the implementation of actions towards the reduction of GHG emissions must not be understood only in a restricted environmental perspective, but also as a holistic indicator of the managers' excellence and the enterprise's strength [26,44]. Anticipating the impacts of climate change and succeeding in efficiently reducing GHG emissions should be viewed as an indicator of the enterprise's performance and alignment with the precepts of sustainable development $[12,18,19,44]$. The effectiveness in implementing sustainability actions does not depends exclusively on traditional competitiveness rules, but also on the knowledge and clear decisions of managers to pursue a sustainable approach. To address issues of climate change, enterprises must innovate their organizational systems, and managers must change their way of thinking, so as to understand global warming not only as an isolated "scientific fact", but as an interconnected "social-economic fact" $[2,26]$.

Regardless of the tête-à-tête communication established with the respondents, it is worthy to note the relatively high levels of "not reported" /"no opinion" expressed by the respondents of the questionnaire. In some cases, the average of "not reported" responses reaches up to $29 \%$ (in the questions regarding investments in sustainability activities; see Table 3), and the average of "no opinion" responses reaches $60 \%$ in the assessment of the degree of difficulty faced by the respondent enterprises throughout the implementation process of the actions proposed (see Table 5). Given the agreement to participate in the survey, one might expect the enterprises' responses to demonstrate a higher level of understanding of sustainable development issues within the business environment. It seems fair to conjecture that even the monitoring of sustainability actions appears to be neglected among these companies, consequently reducing the information available to managers, thus providing new insights to question the dearth of attitudes and efforts related to corporate sustainability.

The capacity of an enterprise to predict social and economic pressures and trends fosters competitive advantages and an ability to obtain direct and indirect gains from the reduction of GHG emissions $[14,15,38]$. Potential risks and opportunities must be identified by enterprises in order to induce a deep comprehension of current and future GHG emissions in the context of a society and economy that is constrained by current and future carbon restrictions $[20,29]$. The adoption of a proactive attitude towards sustainability supposes implementing actions intended to cause structural changes, improve the benefits expected and reduce some financial risks. Furthermore, by contributing to the effective implementation of sustainability actions, particularly to the reduction of GHG emissions, enterprises become part of the "solution" to climate change instead of simply being part of the "problem".

\section{Concluding Remarks}

The set of strategic sustainability actions proposed can be considered robust as it synthesizes global concepts, recommendations and guidelines endorsed by key international sustainable development organizations and thoroughly discussed in worldwide publications related to sustainability. The evaluation scheme, centered on five sustainability indices, was successfully applied to a sample of enterprises to assess the effectiveness of the implementation process of the actions proposed. This approach achieves the objective of analyzing the proactive attitude towards sustainability, as well as the vulnerability (lack of adherence to the sustainable development precepts) of enterprises responsible for a high consumption of electricity.

The flexibility and adaptability of this set of actions and evaluation scheme provides a scalable solution, which qualifies its application to other situations. However, given the dynamic nature inherently associated with the dictums of sustainable development, the approach proposed is limited to the constraints of the basic assumptions considered. Although the approach is robust, it is highly sensitive to the content of the sustainability actions proposed. The evaluation scheme supports changes and the expansion of the actions formulated, as the indices proposed will assume different values 
accordingly, which imposes no difficulty to assess and compare degrees of vulnerability and proactivity. Furthermore, one should bear in mind that the intricacy that is inherent to the concepts associated with sustainability actions does not lead to a straightforward definition of the concepts as occurs with any physical quantity defined based on the fundamental laws of nature.

Despite the fact that the large majority $(85 \%)$ of enterprises participating in this survey recognize the relevance associated with the sustainability actions proposed, the measurement of their degree of commitment, difficulty and investment leads to very discouraging results. Consistently, institutional proactivity produced a low score and institutional vulnerability a very high score. Indeed, this is a clear sign that these enterprises are not yet prepared to overcome the challenges and trends imposed by a strategic sustainable development agenda. These results also highlight the barriers to developing successful corporate sustainability strategies, including the lack of commitment, current investment, specialized knowledge, development and clarification of policies aiming at the reduction of GHG emissions. The concept of implementing strategic actions towards sustainability is an unfamiliar challenge to most enterprises, which presents difficult choices for managers and decision-makers about what type of actions should be taken. These unfavorable results suggest a high necessity to create favorable conditions and policies that enable the development of strategic sustainability actions within the business environment, including the strategic planning and management philosophy of the enterprise.

Considering that trends in cooperate sustainability are characterized by governmental structures and by the economic load and incentives arising from applicable regulations, it seems fair to conjecture that there is a high necessity to create favorable conditions and policies to foster corporate sustainability. Complementarily, enterprises must engage stakeholders, acting as leading catalysts of transformation, thereby fostering an era of sustainable competitiveness. Stakeholder engagement is a critical, yet often overlooked aspect of many enterprises' sustainability efforts. It is up to all stakeholders to encourage a bottom-up and top-down approach in the implementation process of sustainability actions.

In the future, emergent markets and innovative solutions will be rooted in strong values and commitment to sustainability. By embracing a proactive attitude towards sustainability, enterprises benefit from the implementation of strategic actions and prevent these same actions from becoming insurmountable barriers to access new markets.

Acknowledgments: The State Council for S\&T of the State of Rio de Janeiro (FAPERJ, Fundação de Amparo à Pesquisa do Estado do Rio de Janeiro), for the financial support of the first author; the Brazilian Regulator (ANEEL, Agência Nacional de Energia Elétrica) and Light Serviços de Eletricidade S/A, for the opportunity to participate in their joint Regulated R\&D Program (Project Light/ANEEL Project 80/2011).

Author Contributions: While all authors have contributed to the overall development of the paper and analysis/discussion of the results, the first two authors were responsible for designing and writing the article. The third author reviewed the analysis for data consistency, while the last co-authors concentrated on data processing and on filtering the enterprises to meet the pre-established eligibility compliance criteria for participating in the survey.

Conflicts of Interest: The authors declare no conflict of interest.

\section{References}

1. Rockström, J.; Steffen, W.; Noone, K.; Persson, Å.; Chapin, F.S., III; Lambin, E.; Lenton, T.M.; Scheffer, M.; Folke, C.; Schellnhuber, H.J.; et al. Planetary boundaries: Exploring the safe operating space for humanity. Ecol. Soc. 2009, 14, 32.

2. Raworth, K. A Safe and just Space for Humanity: Can We Live within the Doughnut?; Oxfam Discussion Paper; Oxfam International: Oxford, UK, 2012; pp. 1-26.

3. United Nations (UN). Report of the United Nations Conference on the Human Environment. Available online: http:/ / www.un-documents.net/aconf48-14r1.pdf (accessed on 8 August 2016).

4. United Nations (UN). Report of the World Commission on Environment and Development: Our Common Future; Bruntdland Report; United Nations: New York, NY, USA, 1987; pp. 20-51. 
5. United Nations (UN). Report of the United Nations Conference on Sustainable Development; United Nations: New York, NY, USA, 2012; pp. 1-126.

6. Ostrom, E. A general framework for analyzing sustainability of social-ecological systems. Science 2009, 325, 419-422. [CrossRef] [PubMed]

7. Intergovernmental Panel on Climate Change Climate Change (IPCC). Climate Change 2014: Synthesis Report. Contributions of Working Groups I, II and III to the Fifth Assessment Report of the Intergovernmental Panel on Climate Change; Pachauri, R.K., Meyer, L.A., Eds.; IPCC: Geneva, Switzerland, 2014; pp. 1-151.

8. Steffen, W.; Richardson, K.; Rockström, J.; Cornell, S.E.; Fetzer, I.; Bennett, E.M.; Biggs, R.; Carpenter, S.R.; de Vries, W.; de Wit, C.A.; et al. Planetary boundaries: Guiding human development on a changing planet. Science 2015, 347, 6223. [CrossRef] [PubMed]

9. Cornell, S.; Prentice, I.C.; House, J.; Catherine, D. Understanding the Earth System: Global Change Science for Application; Cambridge University Press: New York, NY, USA, 2012; pp. 1-38.

10. Intergovernmental Panel on Climate Change Climate Change (IPCC). The Physical Science Basis. Working Group I Contribution to the Fifth Assessment Report of the Intergovernmental Panel on Climate Change; Stocker, T.F., Qin, D., Plattner, G.-K., Tignor, M.M.B., Allen, S.K., Böschung, J., Eds.; Cambridge University Press: New York, NY, USA, 2013; pp. 3-115.

11. Steffen, W.; Persson, A.; Deutsch, L.; Zalasiewicz, J.; Williams, M.; Richardson, K.; Crumley, C.; Crutzen, P.; Folke, C.; Gordon, L.; et al. The Anthropocene: From global change to planetary stewardship. Ambio 2011, 40, 739-761. [CrossRef] [PubMed]

12. Carbon Disclosure Project (CDP). Business Resilience in an Uncertain, Resource-Constrained World: GDP Global 500 Climate Change Report; Carbon Disclosure Project: London, UK, 2012; pp. 11-39.

13. United Nations Framework Convetion on Climate Change (UNFCCC). Adoption of the Paris Agreement; United Nations Framework Convetion on Climate Change: New York, NY, USA, 2015; pp. 1-31.

14. United Nations (UN). United Nations Global Compact-Guide to Corporate Sustaianbility: Shaping a Sustainable Future; United Nations (UN): New York, NY, USA, 2014; pp. 1-48.

15. Boiral, O. Global warming: Should companies adopt a proactive strategy. Long Range Plan. 2006, 39, 315-330. [CrossRef]

16. Pinkse, J.; Kolk, A. Challenges and trade-offs in corporate innovation for climate change. Bus. Strategy Environ. 2010, 19, 261-272. [CrossRef]

17. Junquera, B.; Brío, J.Á.D.; Fernández, E. Clients' involvement in environmental issues and organizational performance in businesses: An empirical analysis. J. Clean. Prod. 2012, 37, 288-298. [CrossRef]

18. United Nations (UN). IMPACT: Transforming Business, Changing the World-The United Nations Global Compact; United Nations (UN): New York, NY, USA, 2015; pp. 1-48.

19. United Nations (UN). The UN Global Compact-Accenture-CEO Study on Sustainability 2013: Arquitects of a Better World; United Nations: New York, NY, USA, 2013; pp. 1-60.

20. Casarejos, F.; Frota, M.N.; Gil-Penha, L.; Silva, V.V.; Particelli, F. Commitment to emissions restrictions of major consumers of electricity in Brazil. Sustainability 2014, 6, 6377-6399. [CrossRef]

21. Jeswani, H.K.; Wehrmeyer, W.; Mulugetta, Y. How warm is the corporate response to climate change? Evidence from Pakistan and the UK. Bus. Strategy Environ. 2008, 14, 46-60. [CrossRef]

22. Weinhofer, G.; Hoffmann, V.H. Mitigating climate change-How do corporate strategies differ? Bus. Strategy Environ. 2010, 19, 77-89. [CrossRef]

23. Lee, S.Y. Corporate carbon strategies in responding to climate change. Bus. Strategy Environ. 2012, $21,33-48$. [CrossRef]

24. Radomska, J. The concept of sustainable strategy implementation. Sustainability 2015, 7, 15847-15856. [CrossRef]

25. Hoffman, A.J. Getting Ahead of the Curve: Corporate Strategies that Address Climate Change; The Pew Center on Global Climate Change: Ann Arbor, MI, USA, 2006; pp. 1-150.

26. Hoffman, A.J. Climate change as a cultural and behavioral issue: Addressing barriers and implementing solutions. Organ. Dyn. 2010, 39, 295-305. [CrossRef]

27. Intergovernmental Panel on Climate Change Climate Change (IPCC). Managing the Risks of Extreme Events and Disasters to Advance Climate Change Adaptation; Intergovernmental Panel on Climate Change: New York, NY, USA, 2012; pp. 25-542. 
28. European Environment Agency (EEA). Adaptation in Europe: Addressing Risks and Opportunities from Climate Change in the Context of Socio-Economic Developments; European Environment Agency: Luxembourg City, Luxembourg, 2013; pp. 12-61.

29. Agrawala, S.; Fankhauser, S. Economic Aspects of Adaptation to Climate Change: Costs, Benefits and Policy Instruments; The Organisation for Economic Co-operation and Development (OECD): Paris, France, 2008; pp. 1-128.

30. Global Reporting Initiative (GRI). G4 Sustainability Reporting Guidelines; Global Reporting Initiative: Amsterdam, NY, USA, 2013; pp. 3-94.

31. Hoffman, A.J. Climate change strategy: The business logic behind voluntary greenhouse gas reductions. Calif. Manag. Rev. 2005, 47, 21-46. [CrossRef]

32. Kolk, A.; Pinkse, J. Business responses to climate change: Identifying emergent strategies. Calif. Manag. Rev. 2005, 47, 6-20. [CrossRef]

33. Hoffman, A.J. Carbon Strategies: How Leading Companies Are Reducing Their Climate Change Footprint; University of Michigan Press: Ann Arbor, MI, USA, 2007; pp. 1-192.

34. Hoffman, A.J.; Woody, J.G. Climate Change: What's Your Business Strategy?; Harvard Business Review Press: Boston, MA, USA, 2008; pp. 1-115.

35. Agência Nacional de Energia Elétrica (ANEEL). Manual do Programa de Pesquisa e Desenvolvimento Tecnológico do Setor de Energia Elétrica; Internal publication: Brasilia, Brazil, 2012; p. 61.

36. International Organization for Standardization (ISO). ISO 26000: 2010 Guidance on Social Responsibility; International Organization for Standardization: Geneva, Switzerland, 2014.

37. Costa, H.; Baltazar, A. Índice Acge 2011 Responsabilidade Climática em Portugal; Euronatura: Liboa, Portugal, 2011; pp. 1-80. (In Galician)

38. United Nations (UN). Making Global Goals Local Business: A New Era for Responsible Business; United Nations (UN): New York, NY, USA, 2016; pp. 1-32.

39. Confederação Nacional das Indústrias (CNI). Estratégias Corporativas de Baixo Carbono: Gestão de Riscos e Oportunidades; Confederação Nacional das Indústrias: Brasilia, Brazil, 2011; pp. 1-76.

40. German Advisory Council on Global Change (WBGU). World in transition: A social contract for sustainability. In Summary for Policy_Makers; Deutsche Nationalbibliothek: Berlin, Germany, 2011; pp. 1-25.

41. Michaelowa, A.; Michaelowa, K. Climate business for poverty reduction? The role of the world bank. Comp. Int. Stud. 2011, 6, 259-286. [CrossRef]

42. United Nations (UN). Agenda 21, 1992. Available online: https://sustainabledevelopment.un.org/content/ documents / Agenda21.pdf (accessed on 3 February 2016).

43. Sprengel, D.C.; Busch, T. Stakeholder engagement and environmental strategy-The case of climate change. Bus. Strategy Environ. 2011, 20, 351-364. [CrossRef]

44. United Nations (UN). United Nations Global Corporate Sustainability Report; United Nations: New York, NY, USA, 2013; pp. 3-24.

45. Haigh, N.; Hoffman, A.J. Hybrid organizations: The next chapter of sustainable business. Organ. Dyn. 2012, 41, 126-134. [CrossRef]

46. Environment and Human Health (EHHI). LEED Certification: Where Energy Efficiency Collides with Human Health; Environment and Human Health: North Haven, ME, USA, 2010; pp. 6-64.

47. Ehrenfeld, J.R. Eco-efficiency: Philosophy, theory, and tools. J. Ind. Ecol. 2005, 9, 6-8. [CrossRef]

48. Plano Nacional sobre Mudança do Clima (PNMC). Plano Nacional Sobre Mudança do Clima; Governo Federal: Brasilia, Brazil, 2008; pp. 1-132.

49. Ekins, P. Eco-efficiency: Motives, drivers, and economic implications. J. Ind. Ecol. 2005, 9, 12-14. [CrossRef]

50. First, I.; Khetriwal, D.S. Exploring the relationship between environmental orientation and brand value: Is there fire or only smoke? Bus. Strategy Environ. 2010, 19, 90-103. [CrossRef]

51. International Organization for Standardization (ISO). ISO 14000 Environmental Management; International Organization for Standardization: Geneva, Switzerland, 2004.

52. International Organization for Standardization (ISO). ISO 9000 Quality Management; International Organization for Standardization: Geneva, Switzerland, 2015.

53. Lozano, R. Towards better embedding sustainability into companies'systems: An analysis of voluntary corporate initiatives. J. Clean. Prod. 2012, 25, 14-26. [CrossRef] 
54. European Public Real Estate Association (EPRA). European Public Real Estate Association Best Practices Recommendations on Sustainability Reporting; European Public Real Estate Association: Brussels, Belgium, 2011; pp. 26-35.

55. Brazilian Ministry of Science, Technology and Innovation. Available online: http://www.mct.gov.br/index. php/content/view/321144.html\#ancora (accessed on 8 August 2016).

(c) 2016 by the authors; licensee MDPI, Basel, Switzerland. This article is an open access article distributed under the terms and conditions of the Creative Commons Attribution (CC-BY) license (http:/ / creativecommons.org/licenses/by/4.0/). 